\title{
RESUMOS DE TESES
}

\author{
O ESTÁGIO EM ADMINISTRAÇĀO APLICADA À ENFERMAGEM E Á PRÁTICA DE \\ ENFERMAGEM - Sandra de Souza Lima Rocha. FASC/SP - Dissertaçāo de Mestrado \\ - 1991.
}

É um estudo descritivo, onde a autora verifica a aplicação da nova proposta do programa da Disciplina Administração Aplicada à Enfermagem, para os alunos do 4ㅇ ano de Graduação da Faculdade de Enfermagem da PUCCAMP. Utilizamos o modelo de avaliação, o de discrepância de PROVUS (1.971), modificado por LOMBARDO (1.988) e adaptado para a disciplina de Administração. $\mathrm{Na}$ avaliação feita pelos alunos, utilizou-se uma escala de 0 a 5 e os resultados obtidos foram: na área gerencial,o maior percentual está situado no nível $5(48,03 \%)$, considerado satisfatório. Na área assistencial, o maior percentual está situado no nível $5(73,33 \%)$ considerado significativo. Na área de graduação em serviço, o maior percentual no nível 2 (47,69\%) demonstrando acentuada discrepância.

Rua Silvio Carvalhaes, 170 - BI. J, Ap. 11

CEP. 13.060 - Campinas-SP.

\section{O ENFERMEIRO VIVENCIANDO A FORMAÇĀO DE CONDUTA DE ENFERMAGEM - Valéria Castilho - EEUSP-USP - Dissertaçāo de Mestrado - Sāo Paulo - 1991.}

O presente estudo procura revelar o que ocorre na experiência das enfermeiras quando formulam condutas de enfermagem para o tratamento dos problemas dos pacientes, pela utilização do processo de enfermagem. No estudo foi adotada a fenomenologia como vertente metodológica para a análise do vivencial das enfermeiras, procurando explicitar o fenômeno estudado pelos significados emergentes dos relatos de cinco profissionais. Os significados resgatados dos relatos possibilitaram olhar o fenômeno de diferentes formas pelo desvelar da percepção das enfermeiras. Os significados "sentindo a necessidade de estabelecer condutas", "conceituando", "avaliando os resultados", "fatores facilitadores" e "fatores bloqueados"., revelaram a essencialidade do fenômeno formação de condutas de enfermagem.

Escola de Enfermagem da USP

Av. Dr. Enéas de Carvalho Aguiar, 419

CEP 05403 - São Paulo-SP

\section{CONSULTA DE ENFERMAGEM Á GESTANTE: FATORES INTER VENIENTES - Inez Sampaio Nery - UNI-RIO - Tese de Livre Docência, Rio de Janeiro, 1991.}

O trabalho aborda um estudo realizado com vinte enfermeiras que representam o universo das profissionais que executam consulta de enfermagem à gestante em instituições de saúde locais de Teresina (PI). A pesquisa objetivou investigar junto às enfermeiras a sua prática, fatores restritivos e propulsores, percepções e expectativas em relação à referida atividade. A metodologia adotada constou de um estudo exploratório descritivo cujos instrumentos utilizados foram: formulário e roteiro de observação. Através dos resultados, constatou-se a consulta de enfermagem institucionalizada e em expansão, nos serviços de saúde, embora apresente fatores intervenientes ao desenvolvimento da prática. Ficou evidenciado, como realidade da prática na consulta de enfermagem, uma clientela assegurada no grupo de gestantes atendidas nos serviços de saúde local.

Rua Antonio Chaves, 1826

CEP: 64.050 - São Cristóvão - Teresina-PI. 